\title{
Tourism as an alternative source of regional growth in Portugal: a panel data analysis at NUTS II and III levels
}

\author{
Elias Soukiazis • Sara Proença
}

Received: 15 February 2006 / Accepted: 29 May 2007 / Published online: 11 July 2007

(C) Springer-Verlag 2007

\begin{abstract}
The role of tourism is of vital economic importance, particularly for small countries with a privileged geographical location and favourable weather conditions. This paper examines the importance of tourism as a conditioning factor for higher regional growth in Portugal by employing the conditional convergence hypothesis of Barro and Sala-i-Martin, associated with the endogenous growth theory. The panel data estimation approach provides evidence of the positive impact of tourism (through the accommodation capacity) on the growth in per-capita income among the Portuguese regions, increasing the rate of convergence. Therefore, tourism can be considered as an alternative source for stimulating higher regional growth in Portugal, if the supply characteristics of this sector are improved.
\end{abstract}

Keywords Tourism - Conditional convergence - Accommodation capacity · Panel regressions

JEL Classification $\mathrm{C} 23 \cdot \mathrm{D} 12 \cdot \mathrm{L} 83$

E. Soukiazis

Faculty of Economics, University of Coimbra, Coimbra, Portugal

S. Proença

Polytechnic Institute of Coimbra, Coimbra, Portugal

e-mail: sproenca@esac.pt

URL: http://www.saraproenca.planetaclix.pt

E. Soukiazis $(\bowtie)$

Faculdade de Economia, Universidade de Coimbra, Av. Dias da Silva, 165, 3004-512 Coimbra, Portugal

e-mail: elias@fe.uc.pt

URL: http://www4.fe.uc.pt/elas/ 


\section{Introduction}

Tourism activity in Portugal is responsible for approximately $8 \%$ of the gross national product and employs $10 \%$ of the total labour force. Additionally, the revenues from tourism contribute substantially to financing the current account deficit. At a regional level, tourism can help solving the problem of unemployment and replace activities that have lost their competitive advantages (particularly in the agricultural sector). In certain regions (The Algarve in the south of continental Portugal and the Atlantic islands of Madeira and the Azores), tourism is the main tertiary activity, employing a substantial proportion of the labour force. These are all convincing arguments to justify an empirical analysis that measures the impact of tourism on economic growth, particularly at the regional level.

The aims of this paper are, firstly, to examine the importance of tourism to regional growth and, secondly, to study whether tourism can be regarded as a conditioning factor for improving the standards of living of the populations in the Portuguese regions. To do so, the well-known conditional convergence approach is used to test for convergence in per-capita income among the 30 NUTS III and 7 NUTS II Portuguese regions. The empirical analysis uses panel estimation techniques, combining time-series and cross-sectional data from the Portuguese regions at the NUTS II and III levels. To our knowledge, at least for Portugal, there are no studies ${ }^{1}$ that have tested the impact of tourism on regional growth, or have demonstrated how tourism can affect the convergence process between regions.

The remainder of the paper is structured as follows. In Section 2, a brief review of the literature is conducted, revealing the importance of tourism to economic development. Section 3 explains the concepts of convergence that are most commonly used in the literature on growth. Section 4 analyses the disparities in per-capita income among the Portuguese regions over time and gives some information on the accommodation capacity of the tourism sector at regional level. The convergence hypothesis in per-capita income is tested in Section 5, using tourism (accommodation capacity) as the conditioning supply factor for higher growth, followed by a discussion of the results. The final section concludes, summarising the main findings.

\section{The contribution of tourism: a literature review}

The importance of tourism to national economic development has been widely recognised due to its contribution to the balance of payments, production and employment (Williams and Shaw 1991). The balance of payments contribution has received most attention. Tourism improves the "invisibles" component, helps to pay for imports and alleviates the pressures on the balance of payments.

Furthermore, there is an important relationship between economic development and tourism in the sense that tourism stimulates the level of domestic demand. The

\footnotetext{
${ }^{1}$ Ledesma-Rodríguez et al. (2001) provide a study for Brazil and Martín-Eugénio et al. (2004) for the Latin American countries.

型 Springer
} 
ability of the national economy to benefit from tourism depends on the availability of investment to develop the necessary infrastructure, in addition to its ability to supply the services that tourists require (accommodation, food, transportation facilities, entertainment and safety, among others). Therefore, there are strong links between tourism and other economic sectors, including transport, retailing, wholesaling, manufacturing, agriculture, arts and crafts and other services. International capital is also involved in the tourism sector in the form of direct foreign investment in infrastructure and services (hotels, tour operators, transport).

Tourism is also considered to be a sector with potential for the creation of employment. The importance of tourism for employment is strengthened by the relatively labour-intensive nature of tourism and the limited substitution of capital in the production of tourism services.

At the international level, at least with regard to Europe, the evidence confirms (Williams and Shaw 1991) that tourism generates a net distribution of wealth from the North to the South, and from the richer to the poorer states, thus contributing to the convergence process. From a regional perspective, tourism by its nature, can act as a way to distribute development away from the industrial centres towards the less developed regions. In this sense tourism can be used as an instrument for regional development and as a means of reducing regional economic disparities. As tourism can be developed in a short time-span, and with only moderate levels of investment, it can have a rapid and even instantaneous impact on a regional economy.

In the literature on growth, the export-led growth hypothesis postulates that international tourism contributes to growth in two ways; firstly, by inducing efficiency through competition between the local sectors and foreign destinations (Bhagwati and Srinivasan 1979; Krueger 1980); secondly, by facilitating the exploitation of economies of scale in local firms (Helpman and Krugman 1985). Balaguer and Cantavella-Jordá (2002) studied the role of tourism in economic growth for the Spanish economy by using an export-led growth approach for the period 1975-1997. The tourism-led growth hypothesis is confirmed through the testing of co-integration and causality. The results of these authors indicate that economic growth in Spain has been influenced by the persistent expansion of international tourism. Multiplier effects on growth have been found through the expansion of the tourism sector.

Hazari and Sgro (1995) developed a dynamic model showing that favourable world demand for tourism can have positive effects on the long-term growth of a small economy. Recently, Martín-Eugénio et al. (2004) studied the relationship between tourism and economic growth in the Latin American countries from 1985 to 1998. Their analysis is based on a panel data approach with dynamic GMM estimation techniques. They found a significant relationship between economic growth and growth in the tourism sector, conditioned by other macroeconomic variables. Their evidence shows that tourism is favourable to economic growth in medium- or low-income countries, but not necessarily in developed countries.

From the perspective of the welfare effects, there are studies that examine the relationship between tourism and welfare, in which tourists consume non-traded goods and services. Hazari and $\mathrm{Ng}$ (1993) show that in a monopoly framework, tourism may, in fact, be welfare-reducing. On the other hand, Hazari and Kaur (1995) argue that tourism is always welfare-improving. 
From the above literature review, it is clear that tourism can play a valuable role in stimulating higher growth, reducing regional asymmetries, creating employment and bringing about positive externalities that affect (directly or indirectly) other economic activities. This paper will focus on the impact of tourism on regional growth by implementing the convergence approach.

\section{The concepts of convergence}

Different concepts of convergence have been used to study whether different economies tend to achieve equivalent levels of economic development. The controversy about the use of different convergence concepts has largely been empirical, focusing mainly on the validity of the following hypotheses:

(1) The absolute convergence hypothesis

This approach is derived from Solow's (1956) growth model and assumes that poorer economies tend to grow faster than richer ones in earlier stages (due to the lower capital stock held), then in the long run, they all grow at similar rates. Diminishing returns to capital (or constant-returns-to-scale of the reproducible factors) and exogenous technical progress are the standard assumptions of this neoclassical approach. Convergence is unconditional (or absolute) to a common steady state for all economies, whereas divergence is a transitory, short-term phenomenon reflecting adjustments towards a long-run equilibrium level of per-capita income. The further the distance of an economy from its steady state, the faster the growth becomes. Absolute convergence is found when the inverse relationship between the growth in per-capita income and its initial level is confirmed, this result being more likely to occur in a set of economies with similar economic and institutional characteristics. Absolute convergence can be tested empirically by the following regression:

$$
\Delta \ln y_{i, t}=\gamma+b \ln y_{i, t-1}+u_{i, t}
$$

where the growth rate in per-capita income of each economy is related to its initial level, the only factor of convergence. In this equation, $y$ is per-capita income, $i$ the individual economy, $t$ the time, $\gamma$ the common steady state, $b$ the convergence coefficient, $^{2}$ and $u$ the stochastic error. If $b$ is negative $(b<0)$, then it can be said that absolute convergence holds.

(2) The conditional convergence hypothesis

This concept is derived from the new theory of endogenous growth (Barro 1991; Sala-i-Martin 1994). Convergence is conditioned upon some structural factors with increasing-returns-to-scale properties, such as human and physical capital accumulation, technological progress, and innovation, among others. In empirical work, it is often recognised that steady states may differ between economies. If after allowing for such differences, convergence is still found (that is poorer economies grow

\footnotetext{
${ }^{2}$ The parameter $b=\left(1-e^{-\beta T}\right)$ is known as the coefficient of convergence, while $\beta$ expresses the rate or speed of convergence, given by: $\beta=-\frac{\ln (1-b)}{T}$. For further explanation, see Islam (1995) and Tondl (2001).
} 
faster), then this is evidence of conditional $\beta$-convergence. Within this context, convergence is not the rule, but rather the exception, occurring when the economies are able to develop activities with increasing-returns-to-scale characteristics. The hypothesis of conditional convergence can be tested by estimating the following equation:

$$
\Delta 1 n y_{i, t}=\gamma_{i}+b 1 n y_{i, t-1}+c_{j} 1 n X_{i, t}^{j}+u_{i, t}
$$

where $X$ is a vector of $j$ factors that control differences across economies. If $b<0$ and $c_{j} \neq 0$ we can say that the economies exhibit conditional convergence. On the other hand, $b<0$ and $c_{j}=0$ imply that convergence is absolute.

Two main differences distinguish the conditional from the absolute convergence. The first is that economies converge to different steady states, represented by $\gamma_{i}$. The second is that there are some activities that in the long run exhibit increasing-returnsto-scale characteristics, such as human capital, technology and innovation, among others (Barro and Sala-i-Martin 1991, 1995). These activities with increasing returns characteristics counterbalance the diminishing returns to scale property of capital stock in the production function.

(3) The $\sigma$-convergence concept

In addition to these main hypotheses, the $\sigma$-convergence concept is also used to measure the dispersion of per-capita income over time, among different economies. A group of economies is converging if the dispersion of their per-capita income tends to decline over time. The coefficient of variation, given by the ratio of the standard deviation to the sample mean, is normally used to test the hypothesis of $\sigma$ convergence. This concept was first introduced by Barro (1991), to distinguish it from $\beta$-convergence associated with conditional convergence. As Barro stated, $\sigma$ convergence is a necessary, but insufficient, condition for $\beta$-convergence to occur. Both concepts are useful, providing different information on the convergence phenomenon.

In the empirical analysis, we shall focus on testing both hypotheses of absolute and conditional convergence at the NUTS II and III regional levels. Using tourism (through accommodation capacity) as a conditioning factor we can verify its impact on regional growth and its influence on the rate of convergence.

\section{Per-capita income disparities among the Portuguese regions}

Per-capita income differences are significant across regions in Portugal. Table 1 describes the evolution of per-capita income of the Portuguese regions at NUTS II (7 regions) and NUTS III (30 regions) desegregation levels, over a short period of 9 years, from 1993 to 2001, for which reliable data is available. ${ }^{3}$ The relative positions between the 30 NUTS III regions at the beginning and end of the period, as well as in relation to the richest region (Grande Lisboa) are reported to detect any catching-up tendencies.

\footnotetext{
${ }^{3}$ Regional GDP is at current values since there are no regional consumer price indices to deflate GDP.
} 


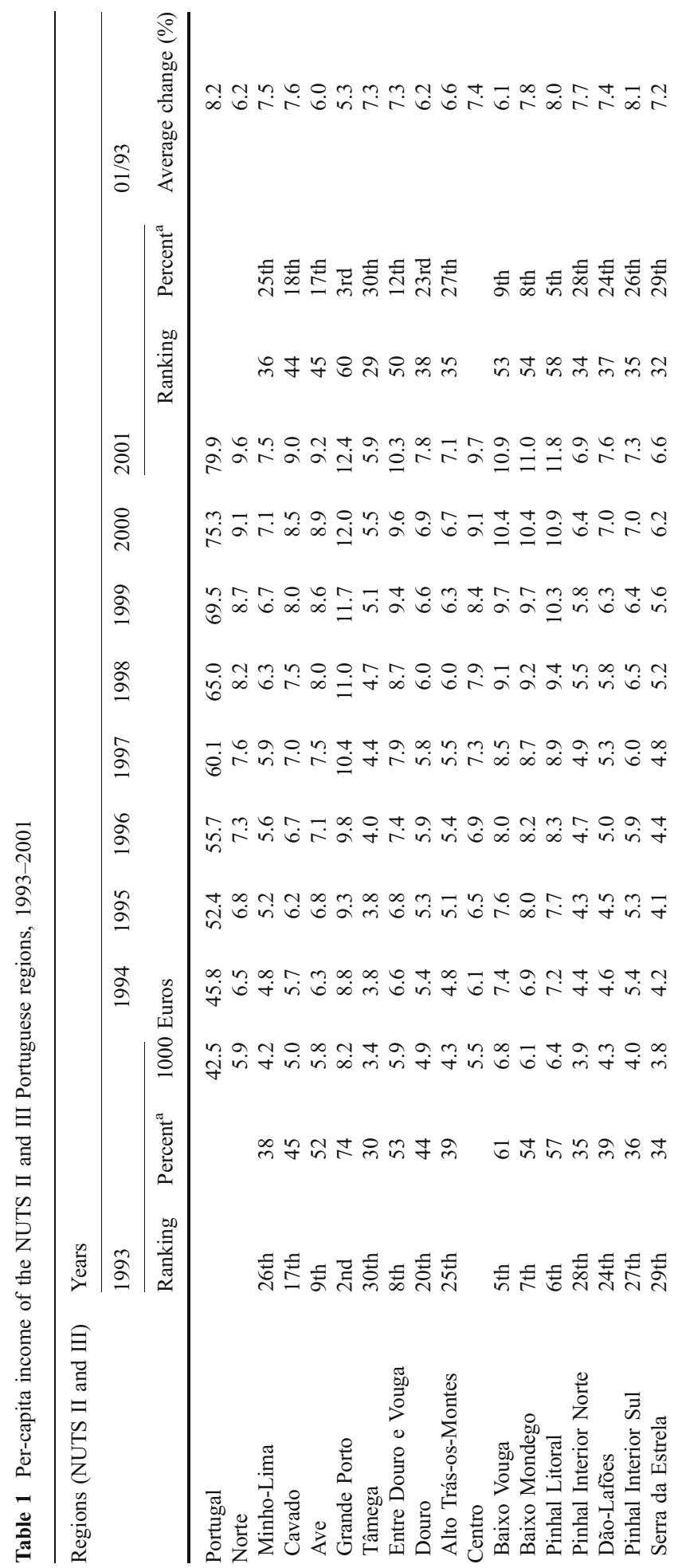




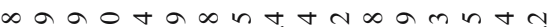
Q $\infty$ r

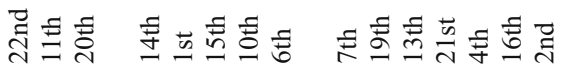

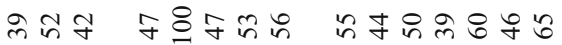
家 no 0 . 9 .

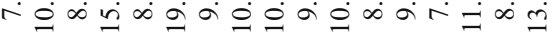

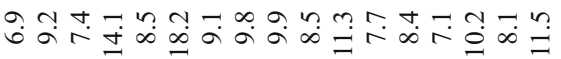

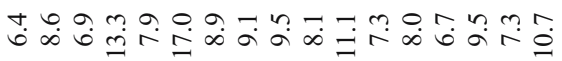

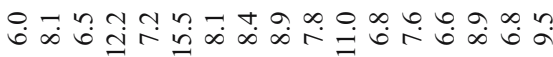

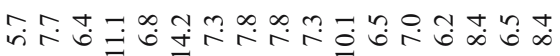

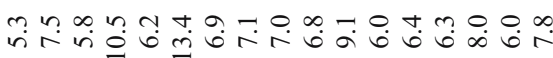
चี

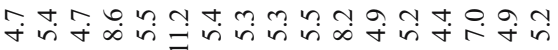
ำ ว

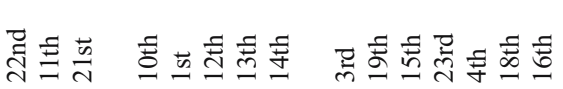

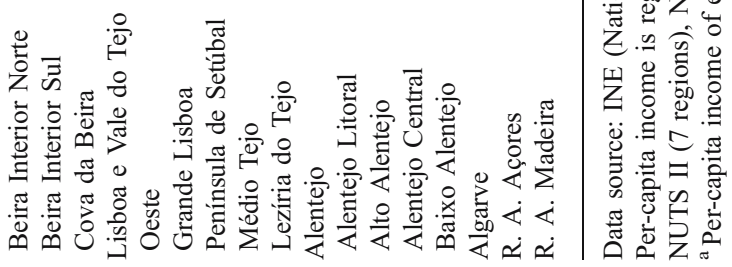


An observation of Table 1 reveals that the richest regions in terms of per-capita income (Grande Lisboa, Grande Porto, Algarve, Alentejo Litoral, Pinhal Litoral, Baixo Mondego and more recently, Madeira) are situated on, or near, the coasts of Portugal, which make them attractive from the point of view of tourism demand. In contrast, the poorest regions (Tâmega, Serra da Estrela, Pinhal Interior Norte, Pinhal Interior Sul, Minho-Lima, Alto Trás-os-Montes) are all situated in the interior of the country and less attractive destinations for tourists in terms of accessibility. From 1993 to 2001, the relative positions of nine regions remained constant, while ten regions improved and eleven declined. It is important to note that the most remarkable improvement (from 16th position in 1993 to 2 nd position in 2001) was achieved by the islands of Madeira, ${ }^{4}$ where tourism activity is predominant. Another region with substantial change in its relative position is Lezíria do Tejo, a non-coastal region, but close to both the sea and to Lisbon, which rose from 14th position in 1993 to 6th position in 2001 .

The relative position of each region with respect to the benchmark (Grande Lisboa) does not show universal improvement. Only seven regions increased their relative position, catching up with the richest region, four remained at the same level and all the others (19 regions) diverged in relation to the benchmark. Therefore, there is no clear evidence of a substantial catching-up process among the Portuguese regions during this period. Madeira is again the region that registered the closest approximation to the richest region. In 1993, Madeira's per-capita income was only $46 \%$ of Lisbon's, but this had risen to $65 \%$ by 2001 . The significance of this development was that Madeira became the region with the second highest per-capita income in Portugal. Madeira also reveals the highest average growth rate (13.2\%) in per-capita income over the whole period, followed by Lezíria do Tejo, which grew by $10.4 \%$ on average.

Figure 1 illustrates, on the other hand, the evolution of regional disparities in Portugal over the period 1993-2001, by using the coefficient of variation ( $\sigma$ convergence). This coefficient measures the dispersion of per-capita income over time and allows the detection of moments of convergence or divergence. ${ }^{5} \mathrm{~A}$ declining value indicates a reduction in regional disparities, an increasing value reveals the widening of regional disparities in terms of per-capita income. As Fig. 1 shows, regional disparities declined slightly at the beginning of the period (19931996), but the disparities later returned to the initial levels, both at NUTS II level (7 regions) and NUTS III level (30 regions). Therefore, there is no solid evidence that a dynamic process of convergence in per-capita income took place among the Portuguese regions over the period considered.

The main purpose of this study is to examine the impact that tourism activity has on regional growth and how tourism affects the convergence process in Portugal at a regional level. The only data ${ }^{6}$ available to us at the NUTS III level (30 regions) is

\footnotetext{
${ }^{4}$ Both Madeira and the islands of the Azores benefit from an autonomous political status (having their own parliament and president), but receive substantial financial support from the central government.

${ }^{5}$ The coefficient of variation, given by the ratio of the standard deviation to the sample mean, is also known as $\sigma$-convergence in the literature on growth.

${ }^{6}$ Receipts from tourism would be the most desirable data to take into consideration, since they affect directly the regional per-capita income, but this data is only available at a national level.
}

Springer 


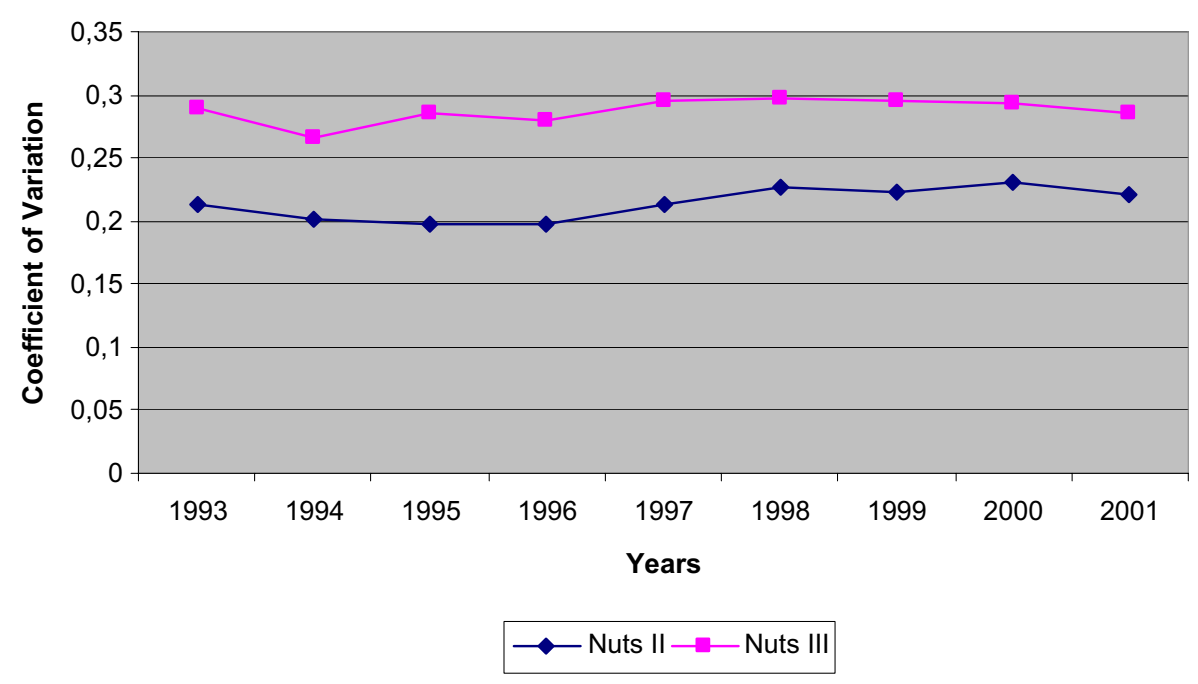

Fig. 1 Dispersion of Per-capita Income among the NUTS II and NUTS III Portuguese Regions, over the Period, 1993-2001. Data source: INE (National Institute of Statistics), Regional Accounts, various issues

obtained from a supply indicator which measures the accommodation capacity expressed by the number of beds available to host tourists. There are two reasons to believe that accommodation capacity is a reasonable proxy for measuring the impact of tourism on regional growth. In a previous study on tourism demand in Portugal Proença and Soukiazis (2005) accommodation capacity was found to be the most significant variable explaining tourism flows in this country. The second reason is that accommodation capacity can be assumed to be exogenous, ${ }^{7}$ thus avoiding endogeneity bias problems that may arise in the estimation process of the convergence equation.

Table 2 presents the available data on the number of beds, showing the accommodation capacity of each region over the period 1993-2001. Ranking the regions according to the higher accommodation capacity (higher number of beds), we observe that the first positions correspond to The Algarve, Grande Lisboa, Madeira and Grande Porto, which are sea-side regions that are highly attractive to tourists. These regions preserve their relative position during the whole period. The lowest rankings with the lowest absolute accommodation capacities are occupied mostly by the interior areas of Portugal (Cova da Beira, Pinhal Interior Norte, Serra da Estrela and Pinhal Interior Sul). From the same ranking, it can be seen that some regions, like Península de Setúbal, Alentejo Litoral and Azores (islands), improved their accommodation capacity significantly by the end of the period. From 1993 to 2001, twelve regions improved their relative position, five maintained their position and the remainder (13) experienced a deterioration of their relative position. During the whole period the total accommodation capacity increased by $16 \%$, corresponding to an annual average growth rate of approximately $1.8 \%$.

The coefficient of correlation between the average change of per-capita income and average change of accommodation capacity is 0.38 , revealing a considerable

\footnotetext{
${ }^{7}$ In the sense that accommodation capacity is mostly determined by exogenous tourism demand.
} 


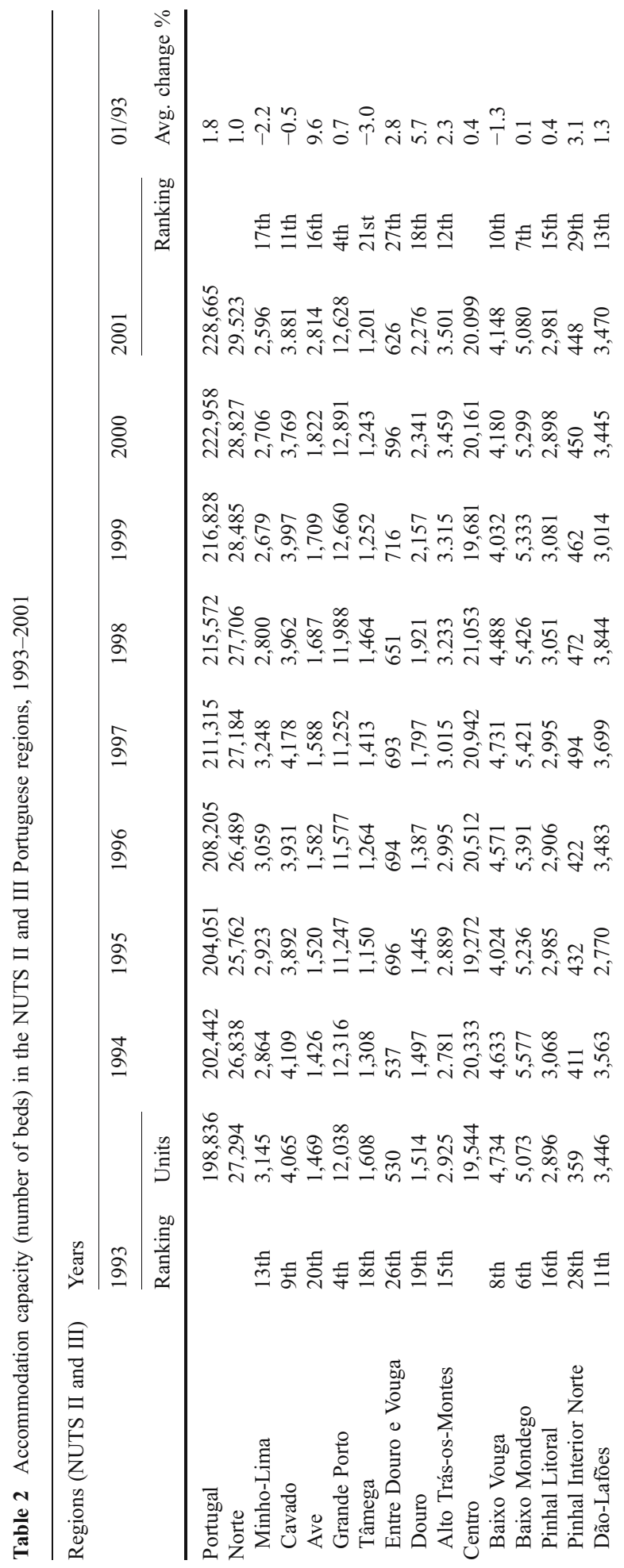




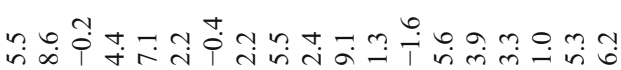

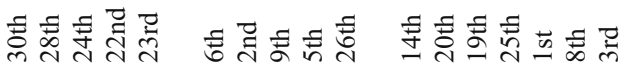

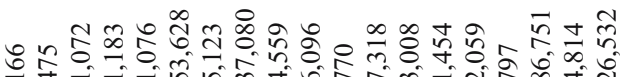

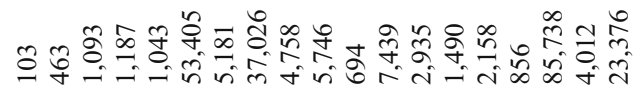

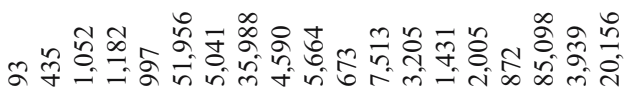

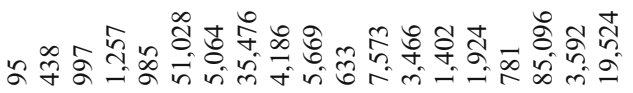

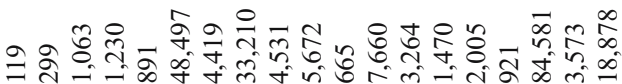

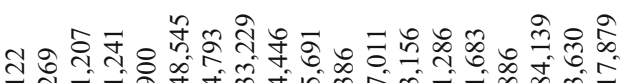

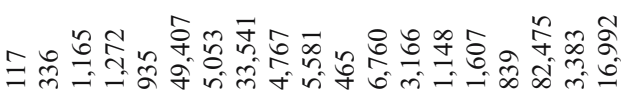

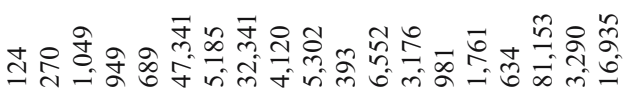

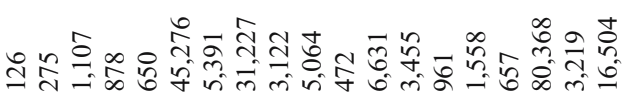

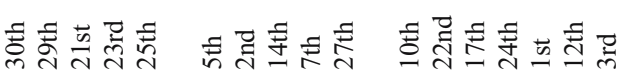

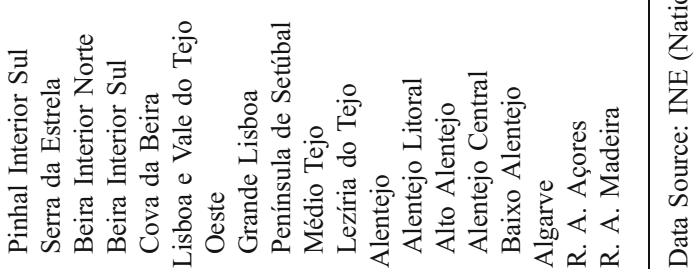


positive association between the two variables during the period 1993-2001. This means that per-capita income and accommodation capacity have proceeded in the same direction across the 30 NUTS III Portuguese regions. Comparing the accommodation capacity with the evolution of per-capita income, it can be observed that the wealthier regions (Grande Lisboa, Algarve, Madeira and Grande Porto) have a higher response to accommodate tourist flows (higher supply capacity).

\section{The importance of tourism on regional growth and convergence}

The conditional convergence equation in per-capita income is used to test the impact of tourism on regional growth at the NUTS III level. ${ }^{8}$ The convergence equation relates the growth in per-capita income $\left(\Delta \ln y_{i, t}\right)$ to the initial level of per-capita income $\left(\ln y_{i, t-1}\right)$ and the accommodation capacity in the tourism sector $\left(\mathrm{TUR}_{i, t}\right)$ as the conditioning factor, given by:

$$
\Delta 1 n y_{i, t}=\gamma_{i}+b \ln y_{i, t-1}+c \ln \mathrm{TUR}_{i, t}+\mathrm{u}_{i, t}
$$

In the convergence Eq. 3, regions are supposed to converge at distinct steady states (given by different intercepts $\gamma_{i}$ ) and the convergence coefficient is expected to be negative $b<0$ and $c \neq 0$ for convergence to be conditional. It would be desirable to introduce other structural factors, such as human and physical capital, to better control the steady state and avoid omitting variable bias. However, this data is not available for this level of regional desegregation. On the other hand, differences in production structures between regions can be captured by the individual dummy variables when fixed effects are considered. It is also necessary to clarify that our aim is not to estimate a well-defined regional growth equation, but rather to test the impact of tourism on regional growth.

Equation 3 is estimated by using panel data estimation techniques, combining 30 regions for a period of 9 years (1993-2001), resulting in a sample of 270 observations. ${ }^{9}$ The estimated results are reported in Table 3. The first part of the table presents the results from absolute convergence (the neo-classical hypothesis), while the second part provides evidence on conditional convergence, testing the significance of accommodation capacity as the conditioning factor for higher regional growth. The familiar panel data estimation methods are used, namely, the Fixed Effects Method (LSDV), which assumes specific individual effects captured by individual regional dummies, ${ }^{10}$ the Random Effects Method (GLS) assuming that regional specific effects are random, and alternatively the system GMM estimator

\footnotetext{
${ }^{8}$ We consider the sample of the 30 NUTS III regions, since it includes tourist (coastal) and non-tourist (interior) regions. In terms of estimation, this sample (in comparison to NUTS II of seven regions) is more appropriate, avoiding sample selection bias. All NUTS II regions are costal regions and the estimated results can be biased.

${ }^{9}$ In fact, only 240 observations are used in the estimations since we have lagged variables and growth rates.

${ }^{10}$ Our regressions contain only individual-fixed effects to capture differences in the production structures between regions which are more important for growth. As Islam (1995) argues, the main usefulness of the panel approach lies in its ability to allow for differences in the aggregate production function across economies. Temple (1999) also states that panel data techniques allow controlling for omitted variables that are persistent over time.
}

望 Springer 
using level moments. ${ }^{11}$ Robust standard errors are used to solve the problem of serially correlated errors within units. ${ }^{12}$

The first part of Table 3 gives evidence of absolute convergence in per-capita income among the 30 Portuguese regions over the period 1993-2001, confirming the notion that absolute convergence occurs among economies (regions or countries) with similar characteristics. The convergence coefficient is negative and statistically significant in all methods of estimation. Considering the results obtained with the GMM estimator, the most efficient method of estimation, ${ }^{13}$ convergence runs at an annual rate of approximately $6.5 \%$. According to this result, it would take 11 years to reduce by $50 \%$ the differences existing in per-capita income across the Portuguese regions. The individual regional dummy variables in the LSDV estimation are jointly significant (see $F$-test), revealing that there are different structures in the production function among the 30 Portuguese regions which have to be taken into account. ${ }^{14}$ When differences in structures are controlled for by the individual dummy variables, convergence is estimated to run at a higher rate, $8.95 \%$ per annum. ${ }^{15}$ In this case, it would take only 8 years to reduce by $50 \%$ the disparities in per-capita income among the Portuguese regions. Therefore, the Fixed Effects estimation method suggests that conditional convergence is faster than absolute convergence.

Our purpose in this study is not to search for the structural factors which might explain the growth in per-capita income. Endogenous growth theory has suggested that human capital, physical capital accumulation, technology and innovation, among other factors, are important conditioning elements to explain growth differentials and to control differences in steady states among different economies (countries or regions). Unfortunately, data for these structural factors with increasing-returns-to-scale properties is not available at NUTS III regional level in Portugal. ${ }^{16}$ Our intention in testing

11 Since our sample size is small, it is better to use the level moments of the system GMM estimator (lagged levels $\ln \left(y_{i, t-2}\right), \ldots$ are used as instruments for $\ln \left(y_{i, t-1}\right)$ ). The accommodation capacity and timedummy variables are additional instruments to capture economic tendencies or structural changes occurring over time. When $\mathrm{N}$ is small, the dynamic Arellano and Bond (1991) GMM estimator (in first differences) is not recommended, since it can lead to substantial finite sample bias.

12 All estimations were made in STATA 9.0.

13 The LSDV and GLS estimates can be biased and inconsistent because $\ln y_{i, t-1}$ can be correlated with the unobserved individual effects. These results are provided for comparison purposes, but show preference to the results obtained from the GMM method that takes account of the endogeneity problem of the regressors.

14 The dummy variables can capture differences in human and physical capital, technology and other resource endowments which are not included in the estimated equations, since there is not statistical information available on these variables at NUTS III level.

15 Influential empirical work by Barro and Sala-i-Martin (1992, 1995), Sala-i-Martin (1994, 1996), Mankiw et al. (1992) and others established 2-3\% as a benchmark estimate of the convergence rate. Other studies established a higher rate of convergence suggesting that its speed is variable and sensitive to time periods, the sample composition and the methods of estimation used. For example, Islam (1995) found a $4.7 \%$ convergence rate for the non-oil countries and 9.7\% for the OECD countries. Evans (1997) obtained estimates of the convergence rate of around 6\% per annum. Caselli et al. (1996) obtained an even higher rate of convergence of around $10 \%$.

${ }^{16}$ Omitted variable bias can be a problem in the estimation process; therefore, the estimation results must be interpreted with caution. For this reason preference is given to the GMM estimation results with robust (small) standard errors. 
Table 3 Convergence in per-capita income among the 30 NUTS III Portuguese regions, 1993-2001

\begin{tabular}{|c|c|c|c|}
\hline Variables & LSDV fixed effects & GLS random effects & GMM estimator \\
\hline \multicolumn{4}{|c|}{ Absolute convergence: $\Delta \ln y_{i, t}=\gamma+b \ln \left(y_{i, t-1}\right)+u_{i, t}$} \\
\hline Constant & $0.2556(8.71)^{*}$ & $0.1293(7.26)^{*}$ & $0.2033(6.22)^{*}$ \\
\hline $\ln \left(y_{i, t-1}\right)$ & $-0.0937(-6.24)^{*}$ & $-0.0288(-3.19)^{*}$ & $-0.0668(-4.20)^{*}$ \\
\hline Convergence rate $(\beta)^{\mathrm{a}}$ & -0.0895 & -0.0283 & -0.0647 \\
\hline $\begin{array}{l}\text { Half way to convergence } \\
\text { (years) }\end{array}$ & 8 & 24 & 11 \\
\hline$R^{2}$ & 0.0403 & 0.0403 & - \\
\hline Number of observations & 240 & 240 & 240 \\
\hline Degrees of freedom & 209 & 238 & 238 \\
\hline$F$ test-Wald test & $\begin{array}{c}F(1,209)=38.93 \\
\text { prob }[0.0000]\end{array}$ & $\begin{array}{l}\text { Wald } \operatorname{chi}^{2}(1)=10.17 \\
\text { prob }[0.0014]\end{array}$ & $\begin{array}{l}\text { Wald } \operatorname{chi}^{2}(1)=17.62 \\
\text { prob }[0.000]\end{array}$ \\
\hline Hansen test & - & & $\begin{array}{l}\mathrm{Chi}^{2}(8)=11.69 \\
\text { prob }[0.165]\end{array}$ \\
\hline $\begin{array}{l}\text { Test for second order serial } \\
\text { correlation } \operatorname{AR}(2)\end{array}$ & 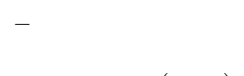 & & $z=1.81$ prob $[0.070]$ \\
\hline \multicolumn{4}{|c|}{ Conditional convergence: $\Delta \ln y_{i, t}=\gamma_{i}+b \ln \left(y_{i, t-1}\right)+c \ln \left(\mathrm{TUR}_{i, t}\right)+u_{i, t}$} \\
\hline Constant & $-0.0330(-0.17)$ & $0.1125(5.75)^{*}$ & $0.1392(4.53)^{*}$ \\
\hline $\ln \left(y_{i, t-1}\right)$ & $-0.1064(-6.22)^{*}$ & $-0.0429(-4.00)^{*}$ & $-0.0701(-4.16)^{*}$ \\
\hline $\ln \left(\mathrm{TUR}_{i, t}\right)$ & $0.0401(1.54)$ & $0.0056(2.31)^{*}$ & $0.0090(2.45)^{*}$ \\
\hline Convergence rate $(\beta)$ & -0.1011 & -0.0420 & -0.0678 \\
\hline $\begin{array}{l}\text { Half way to convergence } \\
\text { (years) }\end{array}$ & 7 & 17 & 10 \\
\hline$R^{2}$ & 0.025 & 0.0610 & - \\
\hline Number of observations & 240 & 240 & 240 \\
\hline Degrees of freedom & 208 & 237 & 237 \\
\hline$F$ test-Wald test & $\begin{array}{l}F(2,208)=20.78 \\
\text { prob }[0.0000]\end{array}$ & $\begin{array}{l}\text { Wald } \operatorname{chi}^{2}(2)=16.07 \\
\text { prob }[0.0003]\end{array}$ & $\begin{array}{l}\text { Wald } \operatorname{chi}^{2}(2)=17.38 \\
\text { prob }[0.000]\end{array}$ \\
\hline Hansen test & - & & $\begin{array}{l}\mathrm{Chi}^{2}(8)=11.45 \\
\text { prob }[0.177]\end{array}$ \\
\hline $\begin{array}{l}\text { Test for second order serial } \\
\text { correlation } \operatorname{AR}(2)\end{array}$ & - & & $z=1.80$ prob $[0.072]$ \\
\hline
\end{tabular}

Values in parentheses are $t$-ratio.

$F$ test: tests the significance of all individual dummy variables.

Wald test is for joint-significance.

GMM is one-step system estimation with robust standards errors and using levels moment conditions [lagged levels $\ln \left(y_{i, t-2}\right) \ldots$ as instruments for $\left.\ln \left(y_{i, t-1}\right)\right]$. Time dummies are additional instruments in the absolute convergence equation, and time dummies and $\ln (\mathrm{TUR})$ are additional instruments in the conditional convergence equation.

Hansen test of over-identifying restrictions in the GMM estimation. The null hypothesis is that the instruments are valid in the sense that they are not correlated with the errors in the estimated equation.

*Indicates that the coefficient is statistically significant at $5 \%$.

${ }^{a}$ The annual convergence rate is given by $\beta=-\ln (1-b) / T$.

${ }^{\mathrm{b}}$ Half of the reduction in regional asymmetries is given by $e^{-\beta T}=-1 / 2$. Therefore, the time to reduce half of the asymmetries is $T=-\ln (2) / \beta$ (see Tondl 2001).

conditional convergence focuses on the importance of tourism activity as a conditioning factor for higher regional growth. The second part of Table 3 presents the estimation results obtained in testing this hypothesis, by introducing the accommodation capacity variable into the convergence equation, reflecting the supply 
dynamism of the tourism sector. In this context, the growth of per-capita income among the Portuguese regions is explained by the convergence factor (initial level of per-capita income) and by the accommodation capacity of each region to host tourists. This latter variable controls differences in the supply structure of the tourism sector among the Portuguese regions, which is mostly determined by external demand and the capacity to invest in accommodation infrastructure.

The evidence from Table 3 is encouraging, showing that the supply capacity of the tourism sector influences positively the growth of per-capita income in the Portuguese regions. The coefficient of the accommodation capacity variable is positive and statistically significant in all methods of estimation, but not in the LSDV case. Another interesting result is that the convergence rate is higher in all methods of estimation compared to the previous case of absolute convergence (first part of Table 3). The GMM estimation (with robust standard errors) gives satisfactory results and all instruments used are valid, as the Hansen test shows. This estimation suggests that convergence in per-capita income is conditional and runs at a slightly higher rate of $6.8 \%$ (instead of $6.5 \%$ in the absolute convergence case). This means that the time to eliminate half of the differences in per-capita income reduces from 11 to 10 years when differences in accommodation capacity in the tourism sector are controlled for. The magnitude of the effect of this variable is also considerable. Every $1 \%$ increase in accommodation capacity in the tourism sector generates approximately $0.01 \%$ increase in per-capita income in the Portuguese regions. In fact, tourism activity induces higher growth in per-capita income and slightly higher convergence, positively influencing the standard of living of the Portuguese regions.

Alternatively, Table 4 reports the results obtained from the estimation of the convergence equation considering the sample of the seven regions of NUTS II desegregation level over the period 1995-2003, for which data is available. Absolute convergence is found in all methods of estimation, but according to the GMM method $^{17}$ convergence runs at $6.8 \%$ per annum, implying that it will take 10 years to achieve a $50 \%$ reduction in the differences in per-capita income among the seven Portuguese regions. The main interest in estimating the convergence equation at this desegregation level is to specify the equation more accurately, by introducing other structural factors, such as capital and labour, for which data is available. ${ }^{18}$ As discussed before, the omission of these variables can bias the estimation results.

The second part of Table 4 presents the results of the conditional convergence estimation, using as conditioning factors the growth of capital formation $g\left(K_{i, t}\right)$, the

\footnotetext{
${ }^{17}$ The time dummy variables were used as additional instruments in the GMM system estimation that may depict structural changes over time. All instruments used are valid as the Hansen test shows.

${ }^{18}$ It would be desirable to include human capital, as well, among the conditioning factors, but data for Madeira and Azores are missing and data for the other regions are not complete for the period considered. Regional data at NUTS II level on gross fixed capital formation (total, millions of euro) and labour (total employment) are taken from Eurostat, Regio database (http://epp.eurostat.ec.europa.eu).
} 
Table 4 Convergence in per-capita income among the 7 NUTS II Portuguese regions, 1995-2003

\begin{tabular}{|c|c|c|c|}
\hline Variables & LSDV fixed effects & GLS random effects & GMM estimator \\
\hline \multicolumn{4}{|c|}{ Absolute Convergence: $\Delta \ln y_{i, t}=\gamma+b \ln \left(y_{i, t-1}\right)+u_{i, t}$} \\
\hline Constant & $-0.2665(-3.14)^{*}$ & $-0.1347(-1.85)^{* *}$ & $-0.2655(-4.51)^{*}$ \\
\hline $\ln \left(y_{i, t-1}\right)$ & $-0.0712(-3.83)^{*}$ & $-0.0423(-2.67)^{*}$ & $-0.0709(-5.69)^{*}$ \\
\hline Convergence rate $(\beta)^{\mathrm{a}}$ & -0.0687 & -0.0414 & -0.0685 \\
\hline $\begin{array}{l}\text { Half way to convergence } \\
\text { (years) }^{b}\end{array}$ & 10 & 17 & 10 \\
\hline$R^{2}$ & 0.0373 & 0.0373 & - \\
\hline Number of observations & 56 & 56 & 56 \\
\hline Degrees of freedom & 48 & 54 & 54 \\
\hline F test-Wald test & $\begin{array}{l}F(1,48)=14.70 \\
\text { prob }[0.0004]\end{array}$ & $\begin{array}{l}\text { Wald } \operatorname{chi}^{2}(1)=7.12 \\
\text { prob }[0.0076]\end{array}$ & $\begin{array}{l}\text { Wald } \operatorname{chi}^{2}(1)=32.32 \\
\quad \text { prob }[0.000]\end{array}$ \\
\hline Hansen test & - & & $\begin{array}{l}\mathrm{Chi}^{2}(8)=6.90 \\
\quad \text { prob }[0.548]\end{array}$ \\
\hline $\begin{array}{l}\text { Test for second order serial } \\
\text { correlation } \operatorname{AR}(2)\end{array}$ & - & & $z=0.40$ prob $[0.692]$ \\
\hline \multicolumn{4}{|c|}{ Conditional convergence: $\Delta \ln y_{i, t}=\gamma_{i}+b \ln \left(y_{i, t-1}\right)+c_{1} g\left(K_{i, t}\right)+c_{2} g\left(L_{i, t}\right)+c_{3} g\left(\mathrm{TUR}_{i, t}\right)+u_{i, t}$} \\
\hline Constant & $-0.1482(-1.86)^{* *}$ & $0.0133(0.23)$ & $-0.0258(-0.26)$ \\
\hline $\ln \left(y_{i, t-1}\right)$ & $-0.0420(-2.39)^{*}$ & $-0.0062(-0.48)$ & $-0.0131(-0.58)$ \\
\hline$g\left(K_{i, t}\right)$ & $0.0703(3.53)^{*}$ & $0.0868(4.05)^{*}$ & $0.1670(1.95)^{* *}$ \\
\hline$g\left(L_{i, t}\right)$ & $0.3998(2.34)^{*}$ & $0.4116(2.28)^{*}$ & $0.4289(2.02)^{*}$ \\
\hline$g\left(\mathrm{TUR}_{i, t}\right)$ & $0.1006(1.55)$ & $0.1082(1.70)^{* *}$ & $0.1522(2.05)^{*}$ \\
\hline Convergence rate $(\beta)$ & -0.0411 & -0.0061 & -0.0130 \\
\hline$R^{2}$ & 0.2775 & 0.3795 & - \\
\hline Number of observations & 56 & 56 & 56 \\
\hline Degrees of freedom & 45 & 51 & 51 \\
\hline F test-Wald test & $\begin{array}{l}F(4,45)=11.13 \\
\quad \text { prob }[0.0000]\end{array}$ & $\begin{array}{l}\text { Wald } \operatorname{chi}^{2}(4)=34.06 \\
\text { prob }[0.0000]\end{array}$ & $\begin{array}{l}\text { Wald } \mathrm{chi}^{2}(4)=55.42 \\
\text { prob }[0.000]\end{array}$ \\
\hline Hansen test & - & & $\begin{array}{l}\mathrm{Chi}^{2}(6)=4.15 \\
\quad \text { prob }[0.656]\end{array}$ \\
\hline $\begin{array}{l}\text { Test for second order serial } \\
\text { correlation } \operatorname{AR}(2)\end{array}$ & - & & $\mathrm{z}=-1.48$ prob $[0.138]$ \\
\hline
\end{tabular}

Values in brackets are $t$-ratio.

$F$ test: tests the significance of all the dummy variables.

Wald test is for jointly significance.

GMM is a one-step system estimation with robust standards errors and using levels moment conditions [lagged levels $\ln \left(y_{i, t-2}\right), \ldots$ as instruments for $\left.\ln \left(y_{i, t-1}\right)\right]$. Time dummies are additional instruments in the absolute convergence equation, and time dummies and $g$ (TUR) are additional instruments in the conditional convergence equation.

Hansen test of over-identifying restrictions in the GMM estimation. The null hypothesis is that the instruments are valid in the sense that they are not correlated with the errors in the estimated equation.

*Indicates that the coefficient is statistically significant at 5\%

**Indicates that the coefficient is statistically significant at $10 \%$

${ }^{\mathrm{a}}$ The annual convergence rate is given by $\beta=-\ln (1-b) / T$.

${ }^{\mathrm{b}}$ Half of the reduction in regional asymmetries is given by $e^{-\beta T}=-1 / 2$ Therefore, the time to reduce half of the asymmetries is $T=-\ln (2) / \beta$ (see Tondl 2001).

growth of labour $g\left(L_{i, t}\right)$ and the growth of tourism (accommodation capacity) $g\left(\mathrm{TUR}_{i, t}\right)$. As can be seen, input factors, represented by capital and labour, have their expected positive effects on growth and they are statistically significant in all methods of estimation. Conditional convergence is obtained, but it is statistically 
significant only in the estimation with Fixed Effects, suggesting a convergence rate of $4.1 \%$ per annum. Our variable of interest, tourism accommodation, has a positive effect on growth, but it is statistically significant only in the GMM estimation. Our evidence suggests that every $1 \%$ increase in accommodation capacity induces an increase of between 0.10 and $0.15 \%$ in per-capita income in the seven Portuguese regions, which is higher than in the NUTS III case. Therefore, there is also evidence that tourism has a substantial impact on regional growth even at a lower desegregation NUTS II level. However, the results of Table 4 should be interpreted with caution due to the small cross-sectional sample (7 regions) and the short timespan considered.

\section{Conclusions}

The main purpose of this study was to test the impact of tourism on regional growth and to learn how tourism affects regional convergence in Portugal. In attempting to attain these objectives, the convergence approach in per-capita income has been used to explain how regional differences have developed over time.

Through the concept of $\sigma$-convergence we have shown that there is not any dynamic process of altering the asymmetries in per-capita income between the 30 NUTS III Portuguese regions, over the period 1993-2001.

By means of the concept of conditional convergence, we found evidence that the Portuguese regions converge to distinct steady states and that tourism (considered through accommodation capacity) is a relevant conditioning factor, improving the standards of living significantly. A 1\% increase in accommodation capacity in the tourism sector induces an increase of roughly $0.01 \%$ in per-capita income in the Portuguese regions.

When the accommodation capacity variable is introduced into the convergence equation, the annual rate of convergence in per-capita income increases from 6.5 to $6.8 \%$ and the time required to eliminate $50 \%$ of the differences in per-capita income is reduced from 11 to 10 years.

The positive impact of tourism on regional growth is also confirmed at the NUTS II level (7 regions), where capital and labour, together with accommodation capacity, are considered as conditioning factors to growth.

From the perspective of economic policy, the analysis as a whole suggests that the improvement in the supply characteristics of the tourism sector is a necessary condition for this sector to contribute positively to regional growth, as well as to speed up the rate of convergence. Therefore, tourism can be considered as an alternative source of growth in Portugal, contributing to the reduction of regional asymmetries.

Acknowledgement We are very grateful to the anonymous referees for their critical comments and suggestions that have helped to improve an earlier version of the paper. 


\section{Appendix}

Map of the 7 NUTS II and 30 NUTS III Portuguese regions

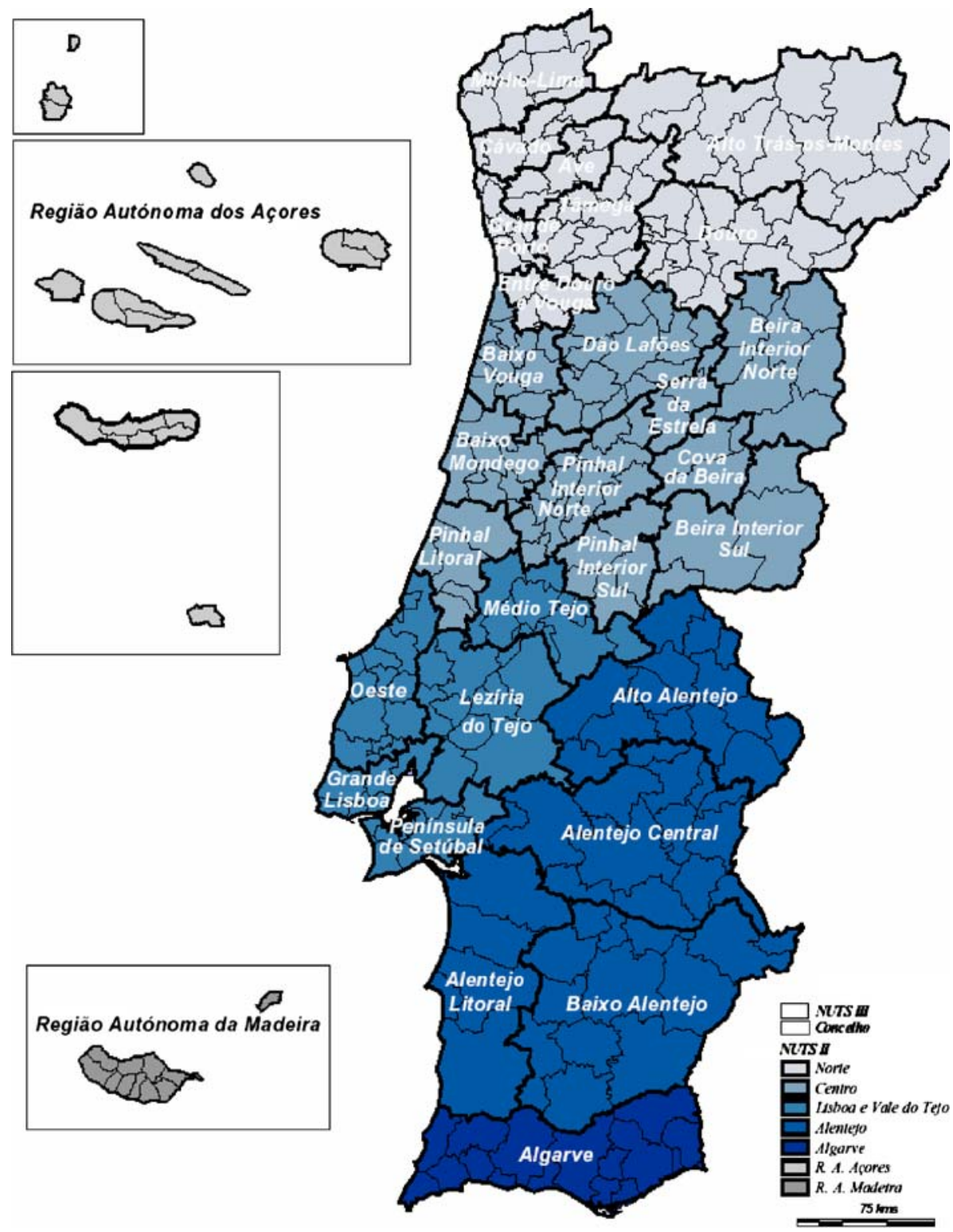

Source: INE (National Institute of Statistics), Regional Accounts, 1995 


\section{References}

Arellano M, Bond S (1991) Some tests of specification for panel data: Monte Carlo evidence and an application to employment equations. Rev Econ Stud 58:277-320

Balaguer J, Cantavella-Jordá M (2002) Tourism as a long-run economic growth factor: the Spanish case. Appl Econ 34:877-884

Barro R (1991), Economic growth in a cross section of countries. Q J Econ. 106(2):407-443 (May)

Barro R, Sala-i-Martin X (1991) Convergence across states and regions. Brookings Pap Econ Act 1:107-182

Barro R, Sala-i-Martin X (1992) Convergence. J Polit Econ 100:223-251

Barro R, Sala-i-Martin X (1995) Economic growth. McGraw-Hill, New York (International Editions)

Bhagwati J, Srinivasan T (1979) Trade policy and development. In Dornbusch R, Frenkel J (eds) International economic policy: theory and evidence. Johns Hopkins University Press, Baltimore, pp 1-35

Caselli F, Esquivel G, Lefort F (1996) Reopening the convergence debate: a new look at cross-country empirics. J Econ Growth 1:363-390

Evans P (1997) How fast do countries converge? Rev Econ Stat 79:219-25

Hazari R, Kaur C (1995) Tourism and welfare in the presence of pure monopoly in the non-traded goods sector. Int Rev Econ Finance 4:77-171

Hazari R, Ng A (1993) An analysis of tourist's consumption of non-traded goods and services on the welfare of the domestic consumers. Int Rev Econ Finance 2:3-58

Hazari BR, Sgro PM (1995) Tourism and growth in a dynamic model of trade. J Int Trade Econ Dev 4:253-256

Helpman E, Krugman P (1985) Market structure and foreign trade. MIT Press, Cambridge

Islam N (1995) Growth empirics: a panel data approach. Q J Econ 110:1127-1170

Krueger A (1980) Trade police as an input to development. Am Econ Rev 70:188-292

Ledesma-Rodríguez F, Navarro-Ibáñez M, Pérez-Rodríguez J (2001) Panel data and tourism: a case study of Tenerife. Tour Econ 7:75-88

Mankiw N, Romer D, Weil D (1992) A contribution to the empirics of economic growth. Q J Econ 107:407-37

Martín Eugénio J, Morales M, Searpa R (2004) Tourism and economic growth in latin american countries: a panel data approach. FEEM Working Paper, University of York, York

Proença S, Soukiazis E (2005) Demand for tourism in Portugal: a panel data approach, CEUNEUROP. Discussion Paper no. 29. Available at http://www4.fe.uc.pt/ceue (February)

Sala-i-Martin X (1994), Cross-sectional regressions and the empirics of economic growth. Eur Econ Rev 38:739-747

Sala-i-Martin X (1996) Regional cohesion: evidence and theories of regional growth and convergence. Eur Econ Rev 40:1325-1352

Solow R (1956) A contribution to the theory of economics. Q J Econ 70:65-94

Temple J (1999) The new growth evidence. J Econ Lit XXXVII:112-156

Tondl G (2001) Convergence after divergence? Regional growth in Europe. Springer, Wien

Williams A, Shaw G (1991) Tourism and economic development: Western European experiences, 2nd edn. Belhaven Press, London 